\title{
Not para-, not peri-, but centric inversion of chromosome 12
}

Asli N Silahtaroglu, Seniha Hacihanefioglu, Gülgün S Güven, Asim Cenani, Jutta Wirth, Niels Tommerup, Zeynep Tümer

\begin{abstract}
A 39 year old male with primary infertility was diagnosed as having Klinefelter syndrome by conventional cytogenetic analysis, which also showed an abnormal chromosome 12. Fluorescence in situ hybridisation (FISH) analysis of the aberrant chromosome using a 12 specific centromeric probe showed a break in the alphoid repeats followed by an inversion within the short arm, resulting in a pseudodicentric chromosome. Further FISH analyses using telomeric and subtelomeric probes showed that the other breakpoint was in the subtelomeric region of the short arm. The karyotype is designated 47,XXY,inv(12)(p10p13.3). To our knowledge this is the first report of a case of "centric inversion".

(F Med Genet 1998;35:682-684)
\end{abstract}

The Genetic and Teratology Research Centre (GETAM), Cerrahpasa Medical Faculty, Istanbul University, Istanbul, Turkey

A N Silahtaroglu

S Hacihanefioglu

A Cenani

Division of Biomedical Sciences, Cerrahpasa Medical Faculty, Istanbul University, Istanbul, Turkey

A N Silahtaroglu S Hacihanefioglu

G S Güven

A Cenani

Department of Medical Genetics, IMBG, Panum

Institute, Copenhagen

University,

Blegdamsvej 3, 2200

Copenhagen N,

Denmark

A N Silahtaroglu

$\mathrm{N}$ Tommerup

Z Tümer

Max Planck Institute

for Molecular

Genetics, Berlin,

Germany

J Wirth

Correspondence to: Dr Tümer.

Received 5 December 1996 Revised version accepted for publication 29 January 1998 inv(12); Klinefelter syndrome

Following the discovery of the specificity of centromeric alpha satellite sequences for each chromosome, ${ }^{1}$ fluorescence in situ hybridisation (FISH) using these sequences became an important tool in resolving chromosome aberrations where conventional banding techniques were inadequate. FISH applications include identifying the chromosome origin of marker chromosomes and determining the localisation or involvement of the centromere and telomere in inversions and translocations. ${ }^{2-4}$ Using FISH, we have identified the breakpoints of a unique inversion involving the short arm of chromosome 12 in a patient with Klinefelter syndrome.

\section{Case report}

A 39 year old male with infertility was referred to our centre suspected of having Klinefelter syndrome. His testes were hypoplastic and he had azoospermia. The parents of the proband had died, but were non-consanguineous and phenotypically normal. There was no history of infertility in the family. The proband's two brothers and two sisters, who had two or three children each, would not cooperate in the investigation.

\section{Materials and methods}

Metaphase chromosomes prepared from PHA stimulated lymphocytes and cultured skin fibroblasts were analysed by standard Giemsa staining and GTL and CBG banding. The commercial FISH probes (Oncor Inc) used
Keywords: centric inversion; centromere fission; were biotin or digoxigenin labelled $\mathrm{D} 12 \mathrm{Z} 3$ (chromosome 12 centromere specific), biotin labelled "All Human Centromere", and digoxigenin labelled "All Telomere" probes. In addition, $100 \mathrm{ng}$ digoxigenin labelled DOP-PCR product $^{5}$ of the YACs y922c8 $(1390 \mathrm{~kb})$, y968f7 $(1580 \mathrm{~kb})$, and y771h4 (1100 kb) mapping to the subtelomeric region of the short arm of chromosome 12 were used. Labelling and hybridisation were carried out according to Kievitis et al. ${ }^{6}$

\section{Results}

Giemsa staining and GTL banding of the initial PHA stimulated lymphocyte chromosomes of the patient suspected of having Klinefelter syndrome showed 47 chromosomes, including an extra $\mathrm{X}$ chromosome and a chromosome 12 with an aberrant short arm, in all the cells analysed (fig 1). FISH analysis of chromosome 12 using D12Z3 showed two signals, one located at the original centromere and the other in the telomeric region (fig 2). The intensity of these two signals were similar to one another, though weaker than the centromeric signal on the normal chromosome 12 . These findings indicated a centromeric fission followed by inversion of the whole short arm of chromosome 12.

Chromosomes were further analysed for the primary constriction and to determine whether the inversion involved the whole short arm or a part of it. With CBG banding, the aberrant chromosome was shown to contain two heterochromatin regions, one located in the original centromeric region and the other in the telomeric region. The primary constriction was always at the telomeric site in 75 lymphocytes and 25 skin fibroblasts analysed. Simultaneous hybridisation with biotin labelled "All Centromere" and digoxigenin labelled "All Telomere" probes showed that the telomeric sequences were not inverted. Further analysis of the telomeric region was carried out using the YAC probes $\mathrm{y} 922 \mathrm{c} 8, \mathrm{y} 968 \mathrm{f} 7$, and y77 1h4, mapping to a region $2 \mathrm{cM}, 5 \mathrm{cM}$, and $15 \mathrm{cM}$ from the telomere, respectively (fig 2). The FISH signals for $\mathrm{y} 922 \mathrm{c} 8$ and $\mathrm{y} 968 \mathrm{f} 7$ were stationary, while the signal for $\mathrm{y} 771 \mathrm{~h} 4 \mathrm{had}$ moved to the original centromeric region of the abnormal chromosome 12. This result indicated that the distal breakpoint has occurred between the YACs y968f7 and y771h4, 5-15 $\mathrm{cM}$ from the telomere.

The karyotype of the patient is designated $47, X X Y, \operatorname{inv}(12)(\mathrm{p} 10 \mathrm{p} 13.3)$ and the extended karyotype is $47, \mathrm{XXY}, \operatorname{inv}(12)(\mathrm{pter} \rightarrow \mathrm{p} 13.3::$ p10 $\rightarrow$ p13.3::q10 $\rightarrow$ qter). 


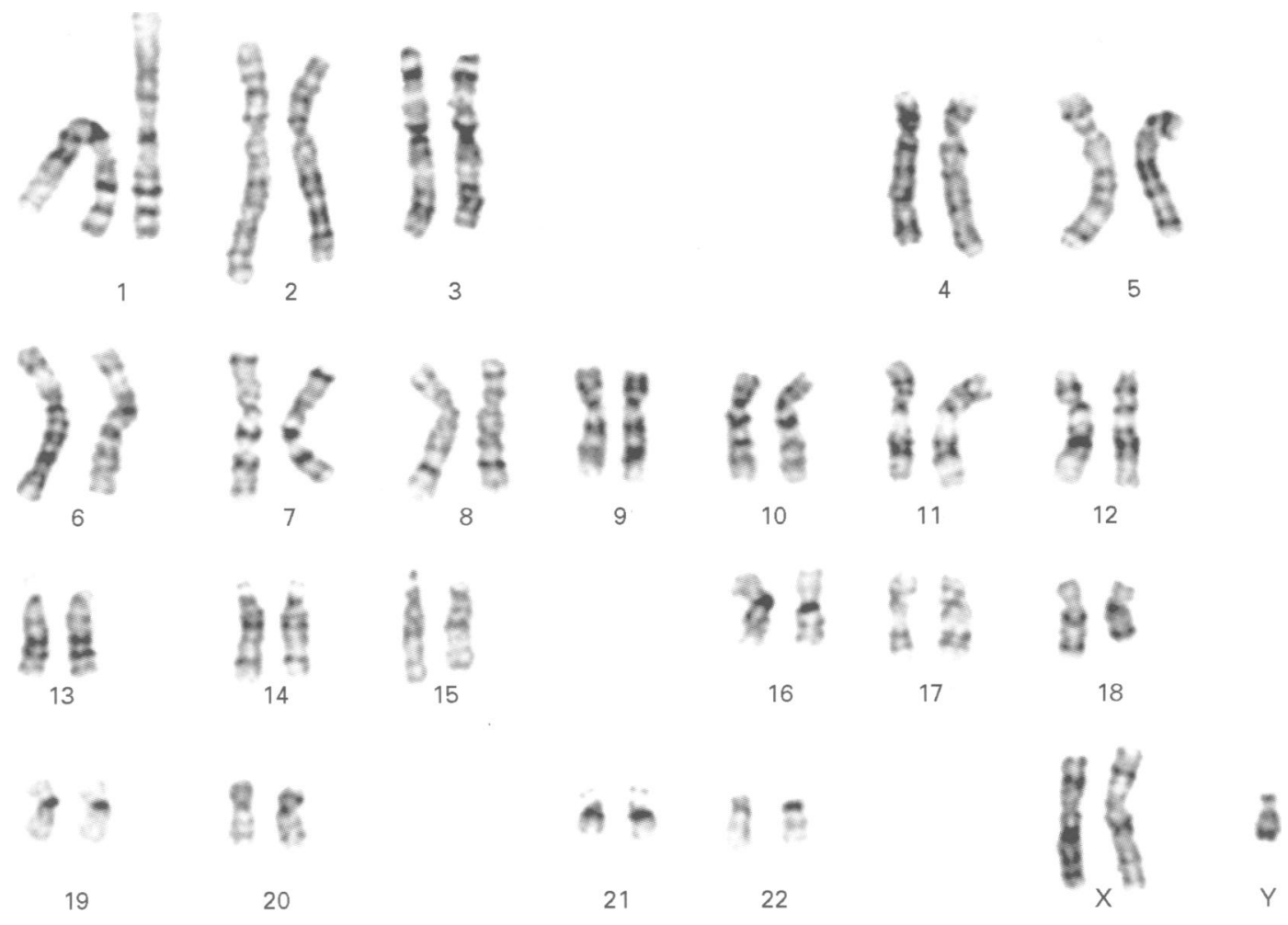

Figure 1 Karyotype of the patient with 47,XXY,inv(12)(p10p13.3) showing the inverted chromosome 12 and the extra $X$ chromosome.

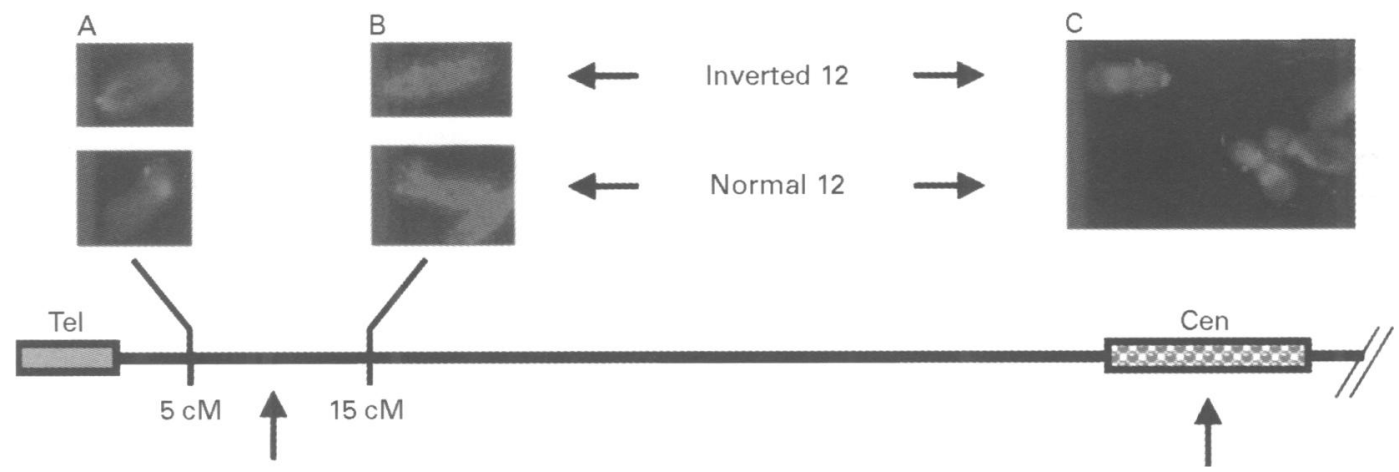

Figure 2 Schematic representation of the short arm of chromosome 12 and the FISH results. The breakpoints are represented by vertical arrows. The proximal breakpoint of the inversion is within the alpha repetitive centromeric region, as shown by the presence of two signals on the inverted chromosome 12 using D12Z3 as FISH probe (C). The distal breakpoint of the inversion is localised to the subtelomeric region using YAC $968 f 7(A)$ and YAC 771h4 (B) as FISH probes. The hybridisation signal of $Y A C 968 f 7(A)$ remains in the telomeric region on the inverted chromosome 12, while the signal of YAC 771 h4 has moved to the centromeric region (B), indicating that the breakpoint has occurred in a region 5-15 cM away from the telomere.

\section{Discussion}

In a patient with Klinefelter syndrome we have identified an inversion of the short arm of chromosome 12, where one of the breakpoints was within the centromeric alpha satellite sequences and the other in the subtelomeric region, 5-15 cM from the telomere (fig 2). Chromosome 12 is one of the chromosomes in which inversions have been reported frequently, including 14 pericentric and 19 paracentric inversions. ${ }^{7-12}$ However, an inversion with a centromeric breakpoint has not been reported previously, either for chromosome 12 or for any other human chromosome. We therefore suggest the term "centric inversion" for this unique case.

Since there is great individual variability in the number of alpha satellite repeats of a specific centromere, the absolute amount of alpha satellite DNA cannot be critical for the function of the centromere. ${ }^{13}$ This is supported by the detection of partial deletion of the alpha satellite sequences without any effect on mitotic stability or meiotic segregation ${ }^{14}{ }^{15}$ and studies suggest that as little as $140 \mathrm{~kb}$ of alpha satellite DNA may be sufficient for centromere function. ${ }^{16}$ Furthermore, alpha satellite repeat sequences could be split into two without functional loss of centromere activity. ${ }^{1317} 18$ In the present case, although it is not possible to deduce the exact amount of the alphoid sequences, the intensity of the FISH signals was almost equal. Either of the centromeres could thus be expected to have sufficient alphoid sequences for normal centromere function. CBG banding results showed that the primary constriction was always in the telomeric region, suggesting that only one of the centromeres was active. However, FISH results contradicted those of CBG banding, as in some 
metaphases the condensed fluorescent signal indicative of the primary constriction ${ }^{19} 20$ was observed in the centromeric region. To define the activity of the centromeres, studies with antibodies specific to CENP-C and CENP-E are required.

Aneuploidy events, including Klinefelter syndrome, have been reported in conjunction with para- and pericentric inversions, implying a possible interchromosomal effect increasing the risk of non-disjunction..$^{912}$ In one patient, Klinefelter syndrome and paracentric inversion of chromosome 12 occurred simultaneously, as in the present case, though involving the long arm. ${ }^{12}$ Various degrees of other infertility problems have also been reported in several male inversion carriers, suggesting an effect of inversions on infertility. ${ }^{911}$ In the present case, though, the sterility is likely to be the result of Klinefelter syndrome.

ANS is supported by the Turkish National Council of Scientific and Technical Research (TUBITAK) through NATO research fellowships (1993). This work was supported by the Research Fund of the Istanbul University (Project No Ö/III/3/130396) and the German Genome Programme/Deutsch Forschunganstalt für Luft- und Raumfahrt eV (grant no 4763), and the EU Commission (BMH4-CT97-2268)

Willard HF. Chromosome-specific organisation of human alpha satellite DNA. Am $\mathcal{F}$ Hum Genet 1985;37:524-32.

2 Silahtaroglu AN, Hacihanefioglu S, Yilmaz S, Tarkan Y, Cenani A, Tümer Z. A supernumarary marker chromosome X identified by in situ hybridiation. Clin Genet 1995; 47:270-3.

3 Gordon LP, Dalton DJ, Martens RP, Tharapel TA, Wilroy SR. Eludication of the centromere involvement in an inverSR. Eludication of the centromere involvement in an inver-
sion (13) by fluorescent in situ hybridisation. $\mathcal{F}$ Med Genet sion (13) by fluo

4 Tharapel AT, Qumsiyeh MB, Martens PR, et al. Identification of the origin of centromeres in whole arm translocations using fluorescent in situ hybridization with alpha satellite DNA probes. Am $\mathcal{F}$ Med Genet 1991;40:117-20.

5 Telenius H, Pelmear AH, Tunnacliffe A, et al. Cytogenetic analysis by chromosome painting using DOP-PCR ampli- fied flow-sorted chromosomes. Genes Chrom Cancer 1992; 4:257-63.

6 Kievitis T, Dauwerse JG, Wiegant J, et al. Rapid subchromosomal localization of cosmids by non-radioactive in situ hybridization. Cytogenet Cell Genet 1990;53:134-6.

7 Haagerup A, Hertz MJ. Pericentric inversion of chromosome 12: a three family study. Hum Genet 1992;89:292-4.

8 Speleman F, Van RN, De Vos E, Hilliker C, Suijkerbuijk RFS, Leroy JG. Molecular cytogenetic analysis of a familial pericentric inversion of chromosome 12. Clin Genet pericentric inversio

9 Pettenati MJ, Rao PN, Phelan MC, et al. Paracentric inversions in humans: a review of 446 paracentric inversions with presentation of 120 new cases. Am $\mathcal{F}$ Med Genet 1995; 55:171-87.

10 Kleckowska A, Fryns JP, Van den Berghe H. Pericentric inversions in man: personal experience and review of the literature. Hum Genet 1987;75:333-8.

11 Madan K. Paracentric inversions: a review. Hum Genet 1995;96:503-15.

12 Singh RP. Klinefelter's syndrome with a 47,XXY,inv(12)(q15q24) karyotype. Clin Genet 1981;19: 188-90.

13 Willard $\mathrm{H}$. Molecular cytogenetics of centromeres of human chromosomes. Proceedings of the 10th International Chromosome Conference, June 1989, Uppsala, Sweden: 47-60.

14 Wevrick R, Earnshaw WC, Howard-Peebles P, Willard HF Partial deletion of alpha satellite DNA associated with reduced amounts of the centromere protein CENP-B in a reduced amounts of the centromere protein CENP-B in a
mitotically stable human chromosome rearrangement. Mol mitotically stable human ch

15 Tümer Z, Berg A, Mikkelsen M. Analysis of a whole arm translocation between chromosomes 18 and 20 using fluorescence in situ hybridization: detection of a break in the centromeric alpha-satellite sequences. Hum Genet 1995;95: 299-302.

16 Brown KE, Barnett MA, Burgtorf C, Shaw P, Buckle VJ, Brown WR. Dissecting the centromere of the human $Y$ chromosome with cloned telomeric DNA. Hum Mol Genet 1994;3:1227-37.

17 Cantú ES, Khan TA, Pai GS. Fluorescence in situ hybridization (FISH) of a whole-arm translocation involving chromosomes 18 and 20 with $\alpha$-satellite DNA probes: detection of a centromeric DNA break? Am $\mathcal{F}$ Med Genet 1992;44: 340-4.

18 Rivera H, Cantu JM. Centric fission consequences in man. Ann Genet 1986;29:223-5.

19 Therman E, Trunca C, Kuhn EM, Sarto GE. Dicentric chromosomes and the inactivation of the centromere. Hum Genet 1986;72:191-5.

20 Sullivan BA, Schwartz S. Identification of centromeric antigens in dicentric robertsonian translocations: CENP-C and CENP-E are necessary components of functional centromeres. Hum Mol Genet 1995;4:2189-97. 